\title{
DEVELOPMENT OF REVERSE PEDALING BRAKING SYSTEM FOR HYBRID TRICYCLE
}

\section{SUYOG KULKARNI, AMOL WADDAMWAR \& RAHUL BHUMKAR}

Research Scholar, Department of Mechanical Engineering, College of Engineering, Pune, India

Received: Apr 10, 2020; Accepted: May 01, 2020; Published: May 26, 2020; Paper Id.: IJAuERDJUN202005

\section{INTRODUCTION}

The main objective behind this project is to build a suitable mode of transportation which would utilize human energy in an efficient way to be used for driving the vehicle that enables to run faster than the present day human powered vehicles. For this purpose, the human strength and weakness, the aerodynamic effect of the fairing, the effectiveness of the drivetrain etc. are taken into consideration. Structural and weight analysis were performed to select the right material for the frame so as to build a vehicle which would be very lightweight but strong enough to sustain high loads exerted by the driver during a ride. Utmost priority has been given to driver safety. The focus has been laid on to fabricate a cost effective, easy to use and easy maintenance cum repairable vehicle with green personal mobility solution. The design of the tricycle is commenced by finalizing the wheel size and overall specifications of the vehicle. The suspension and steering geometries were iterated in CAD. Post this, solid models are created in PTC Creo. These models are then analyzed in ANSYS to check for sustenance of loads and then modified accordingly to have sufficient Factor of Safety. Iterations are also done for integrating all the systems, so 
that they do not interfere and are effectively packaged together. Combining this design methodology with standard engineering design processes enabled us to achieve a perfect match of aesthetics, performance, and ease of operation.

Human powered hybrid vehicles present the new milestone in the realm of "Green Technology". The vehicle that is cheap to buy, cheap to run and can be used from a track racer to a grocery seller and those everybody contributing towards a green environment. In literature, there are two available designs of vehicle i.e. Delta and Tadpole. [1] We have chosen tadpole configuration over delta configuration due to its advantage of more stability during cornering and more availability of grip for both steering and braking. Race Cars always work at the maximum achievable acceleration to finish their race in minimum time. They are usually designed with rear-wheel drive and all-wheel-brake. [2]

A tubular vehicle frame made of AISI 1018 ensures the safety of drivers while making the tricycle light weight. The tricycle can be driven by two riders. Both the riders are provided with individual power-trains to power the vehicle in both single passenger mode and dual passenger mode. The aim of the drive-train model is to deliver the power produced by the riders to the driving wheel most efficiently. The tricycle is also powered by an electric drive. Tricycle uses an ergonomically designed simple four bar mechanism. The suspension system is designed which provides maximum comfort for riders. The braking system is designed for maximum braking performance and safe driving conditions. This document will mainly talk about braking system with its reverse pedaling braking mechanism.

This revolutionary hybrid tricycle design will help to tackle the issue of Global warming as well as ensure the fitness of its riders. This concept can also be applicable to a variety of sectors like internal transportation within industries and educational campuses, golf courses and recreational theme parks.

\section{BRAKING SYSTEM}

A bicycle braking system reduces speed of bicycle and responsible for stopping of bicycle. All wheels have a braking system for maximum braking performance and safe driving conditions. All wheels should lock during the test, and ensure that cable actuated disc brakes is applied in these conditions.

\section{Design Selection Criteria for Braking System}

Brake is an important system for any vehicle in view of safety of commuters. It is true that the vehicle should stop the vehicle in minimum distance after applying the brake and most importantly the vehicle should not topple. Brakes should be efficient, accurate, easy to assemble and repair, low maintenance. Generally, in bicycle three kind of brakes are used

- Rim brake

- Mechanical/Hydraulic disc brake

- Drum brake

Out of the above, hydraulic brake is very accurate and applied with minimum hand force as compared to others. But it is costly and heavy.

A disc brake consists of a metal disc attached to the wheel hub that rotates with the wheel. Callipers are attached to the frame or fork along with pads that squeeze together on the disc. As the pads drag against the disc, the wheel - and thus the bicycle - is slowed as kinetic energy (motion) is transformed into thermal energy (heat). (In basic operation, disc brakes are identical to rim brakes.) A bicycle disc brake may be mechanically actuated, as with a Bowden cable, or hydraulically actuated, or a combination of the two. [3] 
We chose mechanical disc brakes over hydraulic disc brakes due to their light weight, lower cost and easy maintenance. In disc brakes, braking effectiveness is not affected by mud and rain as pads and rotor are near to the wheel. Generally, in bicycles, we have brake levers provided in hands.

In case of bicycle, the motion dynamics of a bicycle will cause a transfer of weight to the front wheel during braking, improving the traction on the front wheel. If the front brake is used too hard, momentum may cause the rider and bike to pitch forward. Light use of the rear brake causes a light skid as the bicycle approaches the limit where pitchover will occur, a signal to reduce force on the front brake. On a low-traction surface or when turning, the front wheel will skid, the bicycle cannot be balanced and will fall to the side instead. [3] The lower relative centre of mass makes it virtually impossible for heavy front braking to flip the bicycle; the front wheel would skid first. [4]

For the hybrid tricycle, which we have focused on in this paper, it can be driven by both pedals and electric motor. The rider has steering handle in both hands, having gear shifter given in the left hand, while throttle for the motor and electronic switch which connects battery supply to the motor are given in right hand. Now, if we give the brake levers in hands as provided in the bicycle, it will increase difficulties for the driver while handling too many controls. Moreover, there is kill switch placed beside driver which can be operated with left hand when required. Thus, it will be difficult for rider to control braking system along with throttling the vehicle.

Considering the above situation, we were searching for the alternate position for the brake lever. Trike has three wheels and brakes are installed on all the three wheels and should apply at same time. Initially, we decided to provide the lever of the front wheel brake in the driver's right hand and the lever of rear wheel brake in left hand. However, motor throttle is given in the driver's right hand as per ergonomic (driver is right handed). While applying brakes, there are chances of throttling, which need to be avoided. To avoid this, we decided to provide all three brake levers in the left hand, but it was going to increase efforts for the application of brakes. Finally, for brakes, we have chosen an alternative and effective braking system than normal one. We used a reverse pedaling braking mechanism in which brakes will apply with the help of legs.

Next challenge for us was how to set the brakes by using legs. As rider's legs are already engaged in pedaling the vehicle, we thought of using the same pedaling activity for application of rear brakes.

\section{Working of Reverse Pedaling Mechanism}

For the reverse pedaling mechanism, we used a chain \& sprocket mechanism for pulling brake cable. On the rider's pedal side, we connected an additional small sprocket having 12 teeth. Then the drive chain's one end is connected to one of the teeth of the sprocket and the other end is connected to the brake wire with the help of a sleeve.

As soon as the rider does the reverse pedaling, the small sprocket mounted on the pedal would rotate in the reverse direction wrapping the drive chain around the sprocket and brake wire would get pulled to apply brakes. When the driver will pedal in a forward direction, the brakes will be released. Figure 1 shows the assembly of the mechanism and fig2 shows different parts in the assembly. 


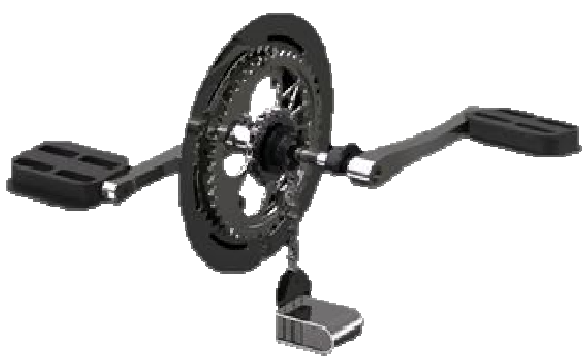

Figure 1: Assembly of Reverse Pedaling Mechanism

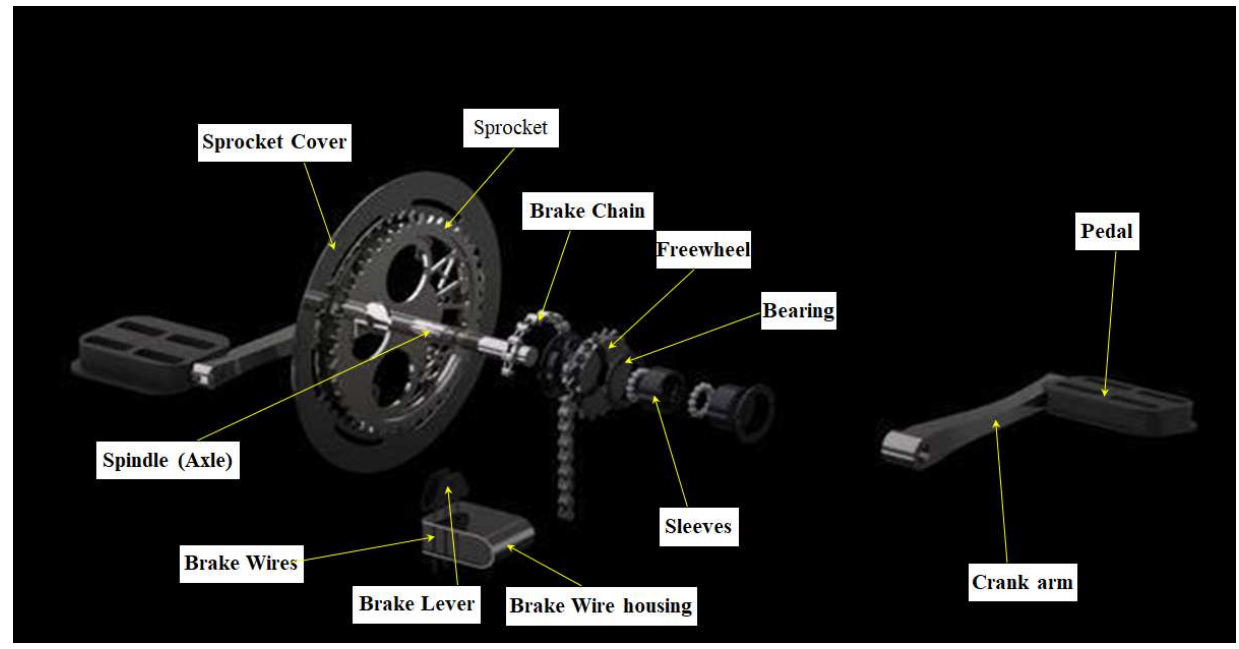

Figure 2: Exploded View of Reverse Pedaling Mechanism

Calculations of Braking System

For the calculations for the required disc size, we need some vehicle level inputs. Following table shows the inputs:

Table 1: Tricycle Input Parameters

\begin{tabular}{|l|l|}
\hline \multicolumn{1}{|c|}{ Input Parameters } & \multicolumn{1}{c|}{ Values } \\
\hline GCW of tricycle & $220 \mathrm{~kg}$ \\
\hline Weight distribution Front : Rear & $45: 55$ \\
\hline Height of CG & 19 ' \\
\hline Wheel Base & 1.25 \\
\hline Max Speed & $30 \mathrm{kmph}$ \\
\hline Diameter of wheels (Front, Rear) & $10 ", 28 ”$ \\
\hline
\end{tabular}

\section{Assumptions}

- $\quad$ Leg force: $98.1 \mathrm{~N}$

- Coefficient of friction between road and tire: 0.02

- Coefficient of friction between brake pad and disc surface : 0.4

- $\quad$ Braking force applied by hands : $5 \mathrm{~kg}$

- $\quad$ Braking force applied by legs : $10 \mathrm{~kg}$ 


\section{Calculated Values}

\section{Target Deceleration: $1.2 \mathrm{~g}$}

From the kinematic equation of motion, we can calculate stopping distance.

Stopping distance $=(\text { speed })^{2} /(2 *$ deceleration $)$

Considering, GCW of tricycle as $220 \mathrm{~kg}$, weight distribution of $45 \%$ on front wheels, and assuming weight is equally distributed between two front wheels in static condition, weight acting on front wheels is,

$\mathrm{W}_{\mathrm{FL}}=\mathrm{W}_{\mathrm{FR}}=22.5 * 220 * 9.81 / 100=485.6 \mathrm{~N}$

Weight on the rear wheel in static condition as per above weight distribution,

$\mathrm{W}_{\mathrm{R}}=220 * 9.81-485.6 * 2=1187 \mathrm{~N}$

Weight distribution is how much weight, or load, each tire has on it at rest. [5]

To calculate, we started with maximum tricycle speed that can be experienced. Longitudinal weight transfer is given by following formula:

Longitudinal Weight Transfer $=($ Weight $*$ Deceleration $(\mathrm{g}) *$ Height of CG $) /($ Wheelbase $)$

Deceleration as targeted is $1.2 \mathrm{~g}$.

Hence, longitudinal weight transfer $=((220 * 9.81) * 1.2 * 0.4826) / 1.25=999.88 \mathrm{~N}$

Weight transferred on front wheels will be divided in left and right front wheel $=999.88 / 2=499.94 \mathrm{~N}$

Table 2: Longitudinal Weight Transfer

\begin{tabular}{|c|c|c|c|}
\hline Tire Location & Static Weight on Tire & $\begin{array}{c}\text { Longitudinal } \\
\text { Weight Transfer }\end{array}$ & $\begin{array}{c}\text { Weight on Tire during Braking } \\
\text { (Normal Load on each wheel) }\end{array}$ \\
\hline Left/ Right Front & $2 \mathrm{X} 485.6 \mathrm{~N}$ & $2 \mathrm{X}+499.94 \mathrm{~N}$ & $2 \mathrm{X} 985.54 \mathrm{~N}$ \\
\hline Rear Wheel & $1187 \mathrm{~N}$ & $-999.88 \mathrm{~N}$ & $187.12 \mathrm{~N}$ \\
\hline Total & $\mathbf{2 1 5 8 . 2 ~ N}$ & & $\mathbf{2 1 5 8 . 2} \mathbf{~ N}$ \\
\hline
\end{tabular}

\section{Torque Required (per wheel)}

Torque on wheel in dynamic condition $=$ Normal load on wheel $*$ Radius of wheel $*$ Coefficient of friction between road and tyre.

\section{Torque generated (per wheel)}

Torque generated at the wheels due to applied braking force $=$ Force acting on brake pads $*$ Effective radius of disc $*$ Coefficient of friction of disc and brake pad

Force acting on brake pads $=$ Effective brake force $*$ Arm length of caliper $/$ Radius of screw

Here, we have measured the arm length of the caliper and radius of screws from the brake caliper.

While, effective brake force $=($ Brake force by hand or leg $) *$ leverage 
Table 3: Comparison of Rear Brake Application with Leg and Rear Brake Application with Hand

\begin{tabular}{|l|c|c|}
\hline \multicolumn{1}{|c|}{ Input Parameters } & Hand Brake & Leg Brake \\
\hline Leverage applied in the lever & 1.5 & 3.5 \\
\hline Torque on front wheel in dynamic condition & $7.55 \mathrm{Nm}$ & $7.55 \mathrm{Nm}$ \\
\hline Effective brake force & $73.58 \mathrm{~N}$ & $110.36 \mathrm{~N}$ \\
\hline Force acting on brake pads & $515.03 \mathrm{~N}$ & $772.54 \mathrm{~N}$ \\
\hline Effective Radius of Disc & $0.073 \mathrm{~m}$ & $0.049 \mathrm{~m}$ \\
\hline Selected Radius of Disc & $\mathbf{0 . 0 9} \mathbf{~ m}$ & $\mathbf{0 . 0 6} \mathbf{~ m}$ \\
\hline Torque generated at the wheels due to applied braking & $9.27 \mathrm{Nm}$ & $9.27 \mathrm{Nm}$ \\
\hline Ratio of Tg:Tr & 1.23 & 1.23 \\
\hline Stopping distance & $2.95 \mathrm{~m}$ & $2.95 \mathrm{~m}$ \\
\hline
\end{tabular}

From table 3, it is clear that the required effective diameter for the disc used for disc brake is more for the hand operated brake than that of leg operated brakes. From the above table, we selected disc brakes, as shown in table 4 , considering leg operated brake lever.

Table 4: Specifications of Brakes

\begin{tabular}{|l|c|c|c|}
\hline & Front Left & Front Right & Rear \\
\hline Type & Mechanical Disc brake & Mechanical Disc brake & Mechanical Disc brake \\
\hline Disc O.D. & $140 \mathrm{~mm}$ & $140 \mathrm{~mm}$ & $140 \mathrm{~mm}$ \\
\hline Disc I.D & $100 \mathrm{~mm}$ & $100 \mathrm{~mm}$ & $100 \mathrm{~mm}$ \\
\hline Disc thickness & $2 \mathrm{~mm}$ & $2 \mathrm{~mm}$ & $2 \mathrm{~mm}$ \\
\hline Calliper type & Lever operated & Lever operated & Lever operated \\
\hline
\end{tabular}

\section{Prototype of Reverse Pedaling Mechanism}

For testing this reverse brake mechanism working, we made a prototype of it by using ABS material in a 3D printing machine. It is shown in Figure 3. The prototype has three wires representing brake cables and sleeve. The lower component will be fixed with the chassis, while the sleeve will be movable. When the driver is pedaling forward, power will be transferred to the rear wheel through chain drive transmission. When the driver pedals in reverse direction, a movable sleeve will pull brake wires leading to application of brakes.

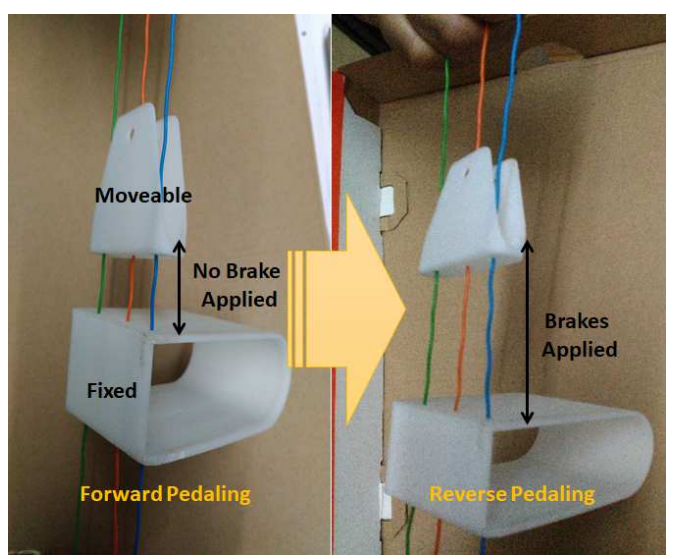

Figure 3: Prototype of Reverse Pedaling Mechanism

\section{Manufacturing and Testing}

For the reverse pedaling mechanism, we used a forging process for the manufacturing of sleeve. We assembled the sprocket on the spindle of the pedal crank and the chain is connected to the sleeve. Brake wires are assembled in the sleeve and finally connected with the disc brake calipers. Fig-4 shows the assembled mechanism in the tricycle. 


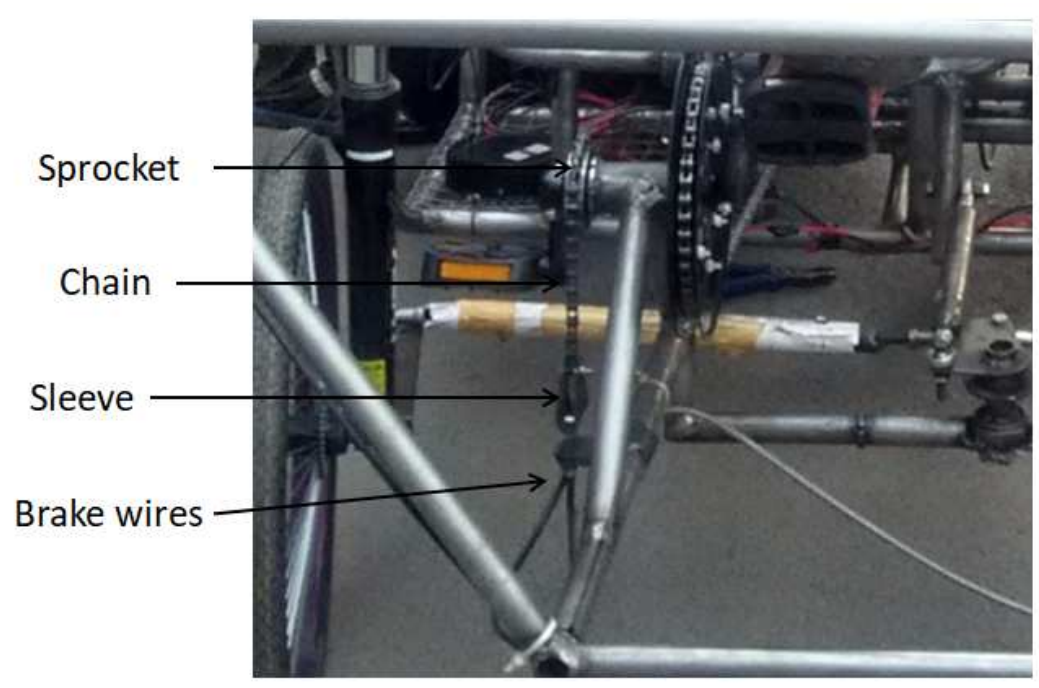

Figure 4: Assembly of Mechanism in Hybrid Tricycle

This mechanism was tested for the stopping distance. The tricycle was run at a constant speed of $25 \mathrm{kmph}$ for a distance of $50 \mathrm{~m}$ and then brakes were applied.[6] Observed stopping distance was $2.7 \mathrm{~m}$.

\section{CONCLUSIONS}

As this is a human powered vehicle, we tried to reduce the efforts of the rider. For ease of rider, placing brakes such that leverage can be taken from the pedals will ensure ease of throttling the vehicle with right hand and with left hand rider can access gear shifter.

The reverse pedaling mechanism, which applies brakes with the help of leg, enabled us to reduce disc diameter. Conversely, if we have selected the same disc diameter as required for hand operated brakes, then stopping distance would have been reduced.

In overall, brakes operated by reverse pedaling results in reduced cost and avoided too many drive controls in the hands of the driver.

\section{ACKNOWLEDGEMENTS}

The authors are thankful to Team Velociracers for the continuous support and provision of the resources required for this study.

\section{REFERENCES}

1. Varun Divekar, Swapnil Gharat, Viraj Kale, Design and development of intelligent co-dependent hybrid human-electric velomobiles, International Journal of Scientific \& Engineering Research, Volume 6, Issue 12, December-2015 ISSN 2229 5518

2. Nikam, Harshal, P. R. E. M. Mishra, and Sayali Bharambe. "Design and Analysis of Brake Rotor with Parameter Optimization." International Journal of Automobile Engineering Research and Development (IJAuERD) 4.4 (2014): 21-30.

3. Reza N. Jazar, "Vehicle Dynamics: Theory and Applications”, Springer, Page 72

4. MOTE, TANUJA P., MEENAL R. MAJGE, and GOURI P. BRAHMANKAR. "MECHATRONICS IN AUTOMOBILES." International Journal of Electrical and Electronics Engineering (IJEEE) 5. 5, (2016) 13-24 
5. Allen, John S. “Using your Brakes”. Retrieved 2010-12-25

6. Bill McCready, President Santana Cycles. "How To: Emergency Stops"

7. Dalvi, Vrushabh Raju, and Nachiket Raju Dalvi. "BATTERY OPTIMIZER MODE CONCEPT." International Journal of Mechanical Engineering (IJME) 7.6(2018) 1-4

8. Herb Adams, "Chassis Engineering”, HP Books, Chapter - Weight Distribution and Dynamics, Page 8

9. SAE NIS, "Efficycle 2015 Rulebook"

10. Pavan, R. S. "A review on hybrid vehicles." Int J Res Eng Technol 2.5 (2014): 59-64. IMPACT: International Journal of Research in Engineering \& Technology (IMPACT: IJRET) 2.5, (2014)59-64 